\title{
Gynecological Symptoms Correlated with Immunohistochemical Aspects of Endometriosis and Adenomyosis
}

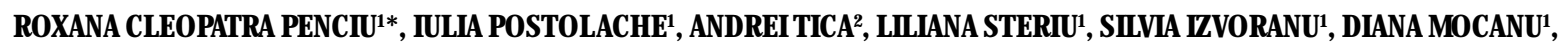 \\ VASILE SARBU ${ }^{3}$, OANA TICA ${ }^{4}$, MARIANA DEACU ${ }^{5}$, GABRIELA BALTATESCU5, 6 , LUCIAN PETCU7, IRINA TICA ${ }^{2 \#, ~}$ \\ VLAD IUSTIN TICA ${ }^{1 \#}$ \\ 'Ovidius University, Faculty of Medicine, Department of Obstetrics and Gynecology, Emergency County Hospital, \\ Campus, 1 Universitatii Alley, 900470, Constanta, Romania \\ 2University of Medicine and Pharmacy Craiova, Department of Clinical Pharmacology, 2 Petru Rares Str., 200349, Craiova, \\ Romania \\ ${ }^{3}$ Ovidius University,Emergency County Hospital, Faculty of Medicine, Department of Surgery, Campus, 1 Universitatii Alley, \\ 900470, Constanta, Romania \\ 4University of Medicine and Pharmacy, Department of Obstetrics and Gynecology, 2 Petru Rares Str., 200349, Craiova, Romania \\ ${ }^{5}$ Ovidius University, Faculty of Medicine, Department of Clinical Pathology, Emergency County Hospital,Campus, 1 Universitatii \\ Alley, 900470, Constanta, Romania \\ ${ }^{6}$ Ovidius University, Research Center - CEDMOG, Faculty of Medicine, Campus, 1 Universitatii Alley, 900470, Constanta, Romania \\ 'Ovidius University, Faculty of Dental Medicine, Department of Statistics,Campus, 1 Universitatii Alley, 900470, Constanta, Romania \\ ${ }^{8}$ Ovidius University, Faculty of Medicine, Department of Internal Medicine, Emergency County Hospital, Campus, 1 Universitatii \\ Alley, 900470, Constanta, Romania
}

\begin{abstract}
Endometriosis is a benign disease characterized by the presence of endometrial tissue outside the uterus. It is more associated to chronic pelvic pain, dysmenorrhea and dyspareunia. Adenomyosis is represented by the presence of endometrial tissue inside the uterine muscle. We studied, in 100 successive patients, immunohistochemical markers CD10, CD34 and KI67 in glandular and in stromal cells, in order to assess the correlation between symptoms and them. We did not find any data reporting these aspects. As CD34 is an angiogenesis marker and Ki67 is an aggressivity marker, pelvic pain could predict a more aggressive disease and with a higher spreading capacity in patients with endometriosis. In the same patients, and dysmenorrhea seems to be related with only with angiogenesis.
\end{abstract}

Keywords: endometriosis, adenomyosis, immunohistochemistry, chronic pelvic pain, dysmenorrhea, dyspareunia

Endometriosis is defined as a benign disease represented by the presence of ectopic endometrial tissue outside the uterine cavity. There are many theories for developing of ectopic lesions, butthere are still controversies related to that [1]. Adenomyosis is defined as the presence of endometrial tissue in the uterine muscle wall. In the past endometriosis and adenomyosis were considered to be the same disease [2].

Endometriosis is usually associated with infertility, chronic pelvic pain, dysmenorrhea and dyspareunia; while adenomyosis can be associated with chronic pelvic pain and - most of the time - with bleedings [3-8]. Pain is, as mentioned, one of the most important and frequent symptoms and, even there are some explanations for that, mechanisms involving pelvic or uterine pain [9] and contractions [10-12] are not entirely clarified.

Because of these important clinical features - and differences - we decided to study for endometriosis and adenomyosis, three immunohistochemical (IHC) biomarkers which are probably related to the two entities - CD10, CD34 and Ki67, as also described by us, previously [13]. The immunohistochemical marker CD10, while expressed by hematopoietic neoplasms like acute lymphoblastic leukemia and follicular lymphomas, it is also expressed by normal endometrial stromal cells and endometrial stromal sarcoma [14]. The immunohistochemical marker CD3 is a transmembrane phosphoglycoprotein, which expresses angiogenesis in tissues [14]. The immunohistochemical marker Ki67 is a marker of cellular proliferation [14].
We decided to study these three markers considering their relation to endometriosis and to determine if patients' symptoms are correlated to their immunohistochemical expression. Another important reason for this study is that we did not find articles which have reported a possible relationship between the three biomarkers and symptoms.

\section{Experimental part}

Materials and methods

In our study we included all 61 successive patients with endometriosis (group 1) and all 39 successive patients with adenomyosis (group 2) admitted and surgically treated in Emergency Clinical County St. Apostle Andrew Hospital Constanta over a period of three years, between 20152017. We studied all of the patients in terms of admission's symptoms, dysmenorrhea, and dyspareunia and immunohistochemical markers: CD10, CD34, Ki67 (in glandular and in stromal cells).

The symptoms studied were chronic pelvic pain, dysmenorrhea and dyspareunia. We excluded from the study, due to some possible described interreferences, patients HIV-positive (with a, past, high regional incidence, especially relevant for the vertical transmission [15]), with infertility treatment (and possible effects of it [16-18]), with previous ovarian pathology/surgery [19], cardiomyopathy [20] or preeclampsia [21-23]. Performed surgery was standard, adapted to the pathology - as well as the analgesia method - no unusual methods, capable to bias the perioperative symptoms [24]. 
All cases were reevaluated by two pathologist and representative samples of each case were selected to test immunohistochemistry biomarkers. Immunohistochemical tests were performed on four ìm-thick sections of formalin-fixed, paraffin-embedded tissue blocks of cases which were included in our study. After the epitope retrieval, tissue sections were incubated with the following antibodies from Biocare Medical (ready-to-use): CD10 (56C6 clone), CD34 (QBEnd 10 clone) and Ki67 (SP6 clone). We used 3,3'diaminobenzidine (DAB) as chromogen, with brown staining. Sections were finally counterstained with Mayer's Hematoxylin. A positive membrane immunostain of stromal cell for CD10 was classified in positive and negative [25]. CD34 immunostain was considered to be positive if there was present a distinctive brown color in the membrane of the endothelial cells or stromal cells. Also, if a brown staining was observed in more than 5 cells, it was considered to be a positive nuclear reaction for Ki67antibody [26]. CD 10 and CD 34 were studied for the stromal cells; meanw hile Ki67 was studied for both glandular and stromal components.

Experimental data were analyzed with statistical software IBM SPSS Statistics 23. The procedures used were: descriptive statistics (to characterize of discrete and continuous variables defined in the data base), nonparametric statistical tests (Chi-squared test for association, correlation between two variables, in order to determine somehow the ratio risk/chance OR, Chi-squared test for the comparison of two proportions) [27-30].

\section{Results and discussions}

IHC biomarker CD10 was positive for all patients of the two groups, confirming the presence of endometrial stromal cells and the diagnosis of endometriosis. CD10 immunohistochemical biomarker is used to detectectopic endometrial tissue presented outside the uterus. Itconfirms the diagnosis of endometriosis for the cases which have uncertain pathological diagnosis [25].

Biomarker CD34 was positive for 18 patients $(29.5 \%)$ in group 1 and $8(20.5 \%)$ patients in group 2. It was negative for 43 patients $(70.5 \%)$ in group 1 and 31 patients (79.5\%) in group 2. We decided to study IHC biomarker CD34 because of the possible relation to endometriosis and adenomyosis - as CD34 expresses angiogenesis - a possible pathophysiological change, in presence of a new tissue in an abnormal position. Wingfield $M$ et al. used IHC biomarker CD34 to identify endothelial cells in endometrium of women with endometriosis and from a control group. He identified an increased number of proliferating endothelial cells in endometrium of women with endometriosis and he concluded that this is the reason why this endometrium can implant and survive in ectopic sites [31]. Meenakshi $M$ et al. described a vascular involvement in adenomyosis [32].

Ki67 for glandular cells was positive for 25 patients (41\%) in group 1 and for 13 patients (33.3\%) in group 2. It was negative for 36 patients (59\%) in group 1 and 26 patients (66.7) in group 2. Ki67 for stromal cells was positive for 54 patients (97.4\%) in group 1 and all patients in group 2. It was negative for 7 patients (11.5\%) in group 1 and one patient (2.6\%) in group 2. The Ki67 marker is an expression of increased cell dissemination activity and it is directly correlated with the severity (stage) of endometriosis [26, 33]. J ehn-Hsiahn Yang et al. stated that a high Ki67 index can predict the developing of an adenomyotic lesion [34].

Regarding chronic pelvic pain, in group 1, 14 patients had pain and 14 patients were asymptomatic. In group 2 , there were 12 patients with pain and 27 patients without it.
- 17 patients with pain, and one asymptomatic. For group 2 , there were 8 patients positive for CD34 - one with pelvic pain and 7 asymptomatic (fig. 1). IHC biomarker CD34 was negative for 30 patients with pelvic pain, and for 13 asymptomatic patients, in group 1. It was also negative in 11 patients with pelvic pain and in 20 asymptomatic patients, in group 2.

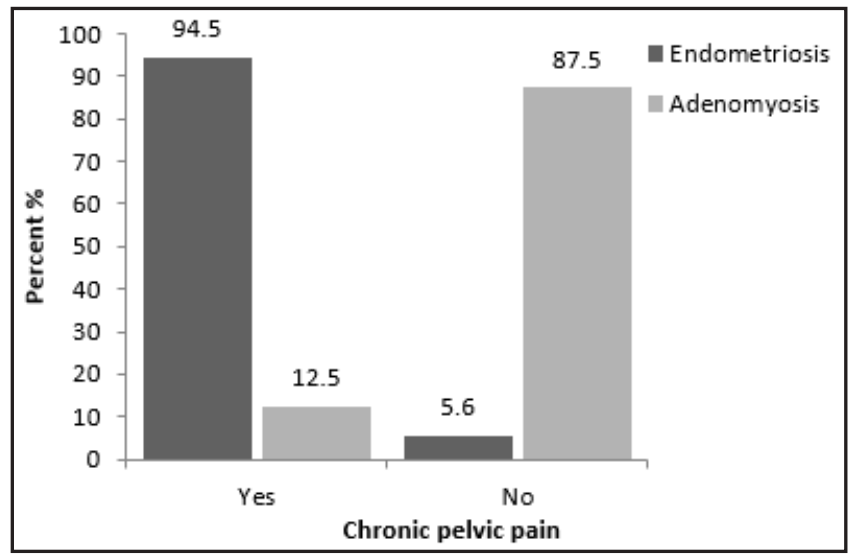

Fig. 1. Repartition (\%) of patients with CD34 positive and chronic pelvic pain in both groups

There was a statistically significant difference according to the presence or the absence of chronic pelvic pain in group 1 in patients with CD34 positive or negative $(p=$ $0.037<0.05)$. Hence, there could be a higher probability of patients with CD34-positive samples to express pain. Or, in reverse, patients with more pelvic pain could harbor a disease with more angiogenesis - so, more aggressive.

A non-significant statistical difference according to the presence or the absence of chronic pelvic pain was found in group 2 ( $p=0.209>0.05)$.

Biomarker Ki67 for glandular cells was positive, in 14 patients with chronic pelvic pain, and in 11 patients without it. It was negative in 33 patients with pain and in 3 patients without. In group 2, this biomarker was positive in 5 patients with pain and in 8 patients without. Conversely, it was negative, in this group, for 7 patients with pelvic pain and in 19 individuals without.

There was a statistically significant difference according to the presence or the absence of chronic pelvic pain in group 1 in patients with Ki67 for glandular cells positive or negative $(p=0.001<0.05)$. We could observe, therefore, a correlation in-between the positivity of this immunomarker and the presence of chronic pelvic pain. A non-significant statistical difference was noted in group 2 $(p=0.462>0.05)$.

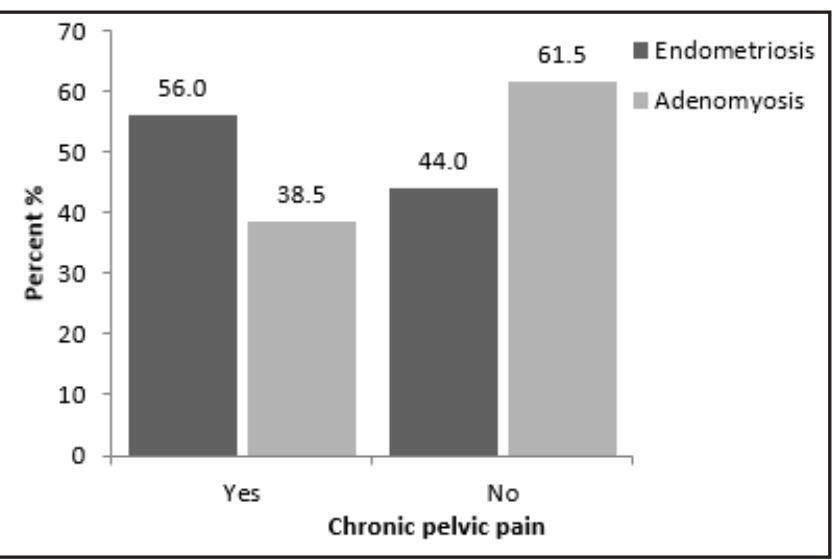

Fig. 2.Repartition (\%) of patients with chronic pelvic pain Ki67 positive in glandular cells in both groups 


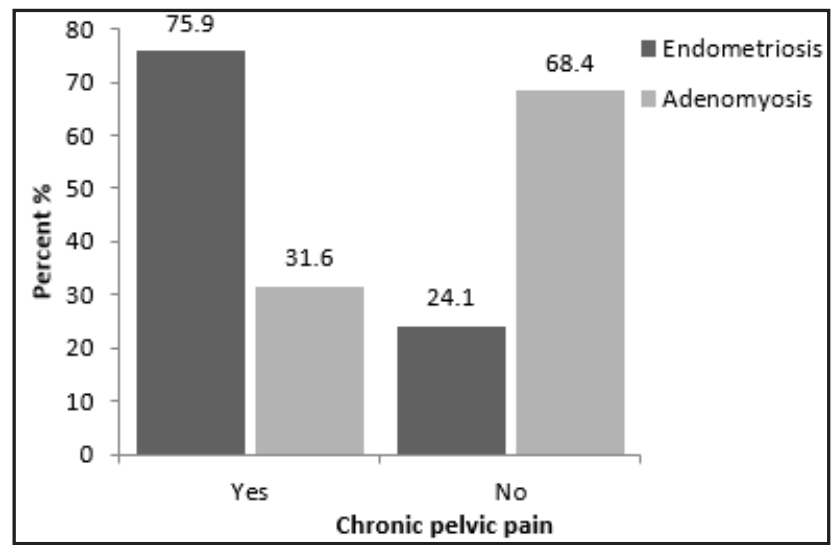

Fig.3. Repartition (\%) of patients with chronic pelvic pain and Ki67 positive in stromal cells in both groups

Biomarker Ki67 for stromal cells was positive for 43 patients in group 1 with chronic pelvic pain and in 11 patients without pain. It was, in the same group, negative for 6 patients with pelvic pain and one asymptomatic patient. This biomarker was positive for 12 patients with the symptom and in 26 individuals without. It was negative only for one asymptomatic patient.

There was no statistically significant difference according to the presence or the absence of chronic pelvic pain in group 1 in patients with Ki67 for stromal cells positive or negative $(p=0.562>0.05)$. A non-significant statistical difference was equally noted in group $2(p=0.499>0.05)$.

Another important symptom for admission in hospital was dysmenorrhea. For group 1, 42 patients had dysmenorrhea, while in group 2 , only 10 patients had this symptom.

As we noticed earlier biomarker CD10 was positive for all patients with or without dysmenorrhea, for both of the groups.

In group 1, biomarker CD34 was positive for 16 patients with dysmenorrhea and for 2 patients without this symptom. IHC CD34 was negative for 26 patients with dysmenorrhea and for 17 patients without the symptom. In group 2, it was positive for one patient with the symptom and for 7 patients without it (fig. 4). In the same group, IHC CD34 was negative for 9 patients with dysmenorrhea and 22 patients without the symptom.

There was a statistically significant difference according to the presence or the absence of dysmenorrhea in group 1 in patients with CD34 positive or negative $(p=0.029<$ $0.05)$. It seems that dysmenorrhea is associated with the expression of CD34 in patients of group 1. For group 2, even if the absence of this symptom appeared to be associated to CD34 expression the statistical difference was non-significant $(p=0.340>0.05)$.

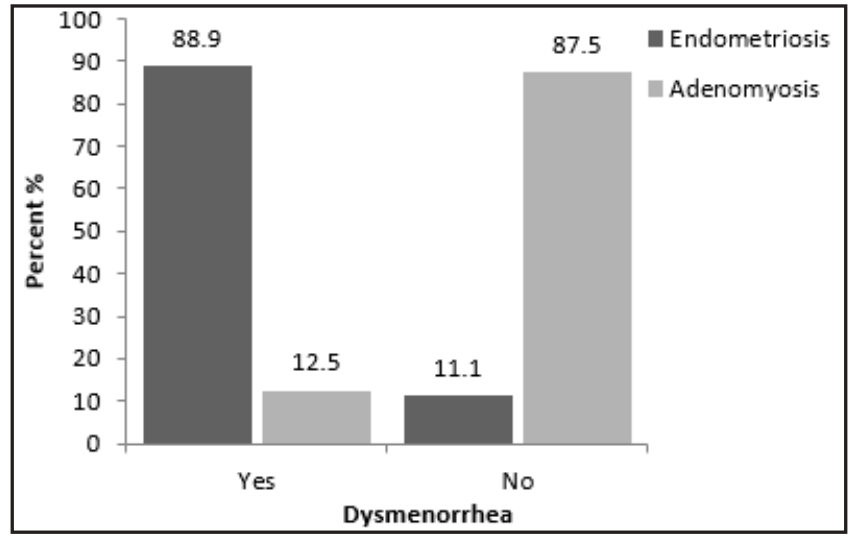

Fig. 4. Repartition (\%) of patients with CD34 positive and dysmenorrhea in both groups
Biomarker Ki67 for glandular cells was positive for 10 patients with dysmenorrhea and 15 patients without this symptom, in group 1. IHC Ki67 for glandular cells was negative for 31 patients with dysmenorrhea and 5 patients without it, in the same group. In group 2, IHC Ki67 for glandular cells was positive for 4 patients with dysmenorrhea and 9 patients without dysmenorrhea (fig. 5). IHC Ki67 for glandular cells was negative for 6 patients with dysmenorrhea and 20 patients without this symptom in group 2. It seems that the absence of dysmenorrhea, in both groups, is more associated to a positive expression of IHC biomarker Ki67 in glandular cells.

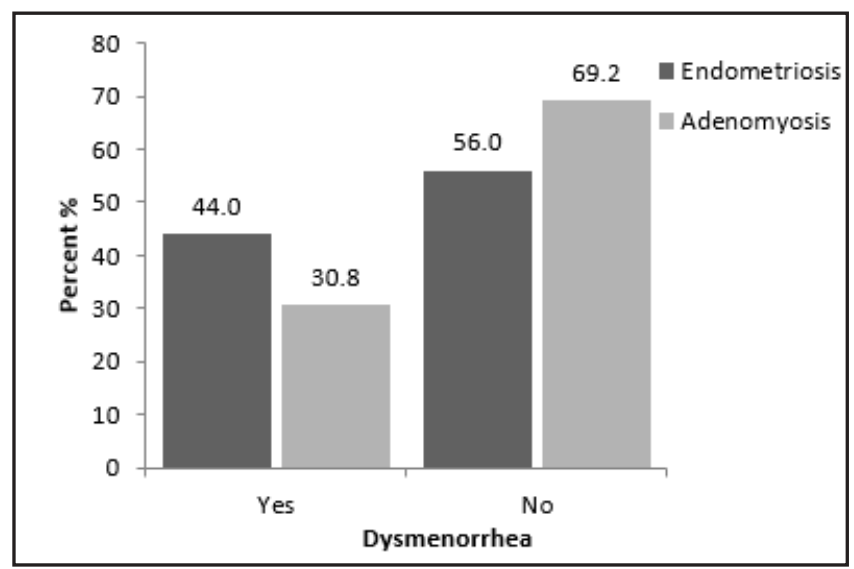

Fig. 5. Repartition (\%) of patients with dysmenorrhea and Ki67 positive in glandular cells in both groups.

There was a statistically significant difference according to the presence or the absence of dysmenorrhea in group 1 in patients with Ki67 for glandular cells positive or negative $(p<0.001<0.05)$. The same correlation was, statistically, non-significant in group $2(p=0.604>0.05)$.

Biomarker Ki67 for stromal cells was positive for 39 patients with dysmenorrhea and 15 patients without it, of group 1. Biomarker Ki67 for stromal cells was negative in group 1, in 3 patients with dysmenorrhea and 4 patients without the symptom. IHC Ki67 for stromal cells was positive for 10 patients in group 2 with dysmenorrhea and 28 patients of group 2 without the symptom (fig. 6). In the same group, it was negative only in one patient without dysmenorrhea.

There was no statistically significant difference according to the presence or the absence of dysmenorrhea in group 1 in patients with Ki67 for stromal cells positive or negative ( $p=0.114>0.05$ ). The same correlation was statistically non-significant, in group $2(p=0.552>0.05)$.

Dysmenorrhea was associated mostly to a positive expression of IHC Ki67 in stromal cells of patients in group 1 , contrarily to group 2 , in which the positivity is associated to absence of this symptom.

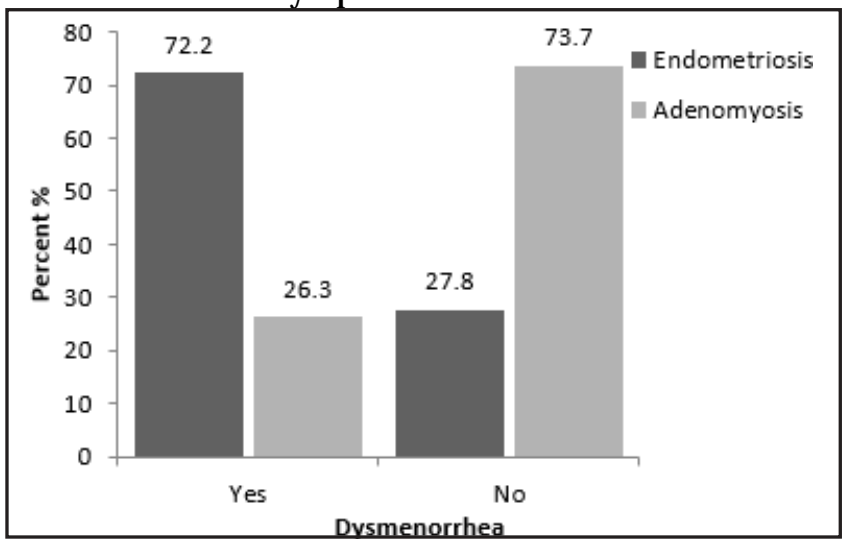

Fig. 6. Repartition (\%) of patients with dysmenorrhea and Ki67 positive in stromal cells in both groups 
Twenty-nine patients of group 1 and 6 patients of group 2 had dyspareunia as a symptom for the hospital admission.

Biomarker CD10 was positive for all the patients - with or without dyspareunia -in both groups.

Biomarker CD34 was positive for 9 patients with dyspareunia and for 9 patients without dyspareunia in group 1. IHC CD34 was negative in group 1 , in 20 patients with dyspareunia and 23 patients without the symptom. Biomarker CD34 was positive only for the 8 patients in group 2, without dyspareunia (fig. 7). In group 2, it was negative for 6 patients with dyspareunia and 25 patients without the symptom.

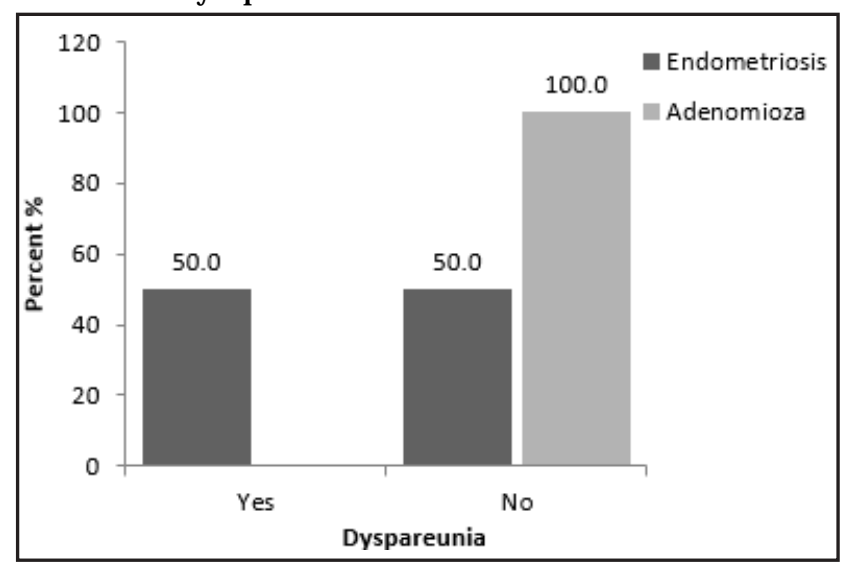

Fig. 7. Repartition (\%) of patients with CD34 positive and dyspareunia in both groups.

There was no statistically significant difference according to the presence or the absence of dyspareunia in group 1 in patients with CD34 positive or negative $(p=$ $0.804>0.05)$. The same insignificant difference was observed in group $2(p=0.176>0.05)$.

Biomarker Ki67 for glandular cells was positive for 6 patients with dyspareunia and 19 patients without the symptom, in group 1. Biomarker Ki67 for glandular cells was negative for 22 patients with dyspareunia and 14 patients without it, in the same group. In group 2, IHC Ki 67 for glandular cells was positive for 3 patients with dyspareunia and 10 patients without this symptom. In the same group, biomarker Ki67 for glandular cells was negative for 3 patients with dyspareunia and 23 patients without it. The absence of dyspareunia was, therefore, associated more to the IHC Ki67 expression in glandular cells, for patients of both groups (fig. 8).

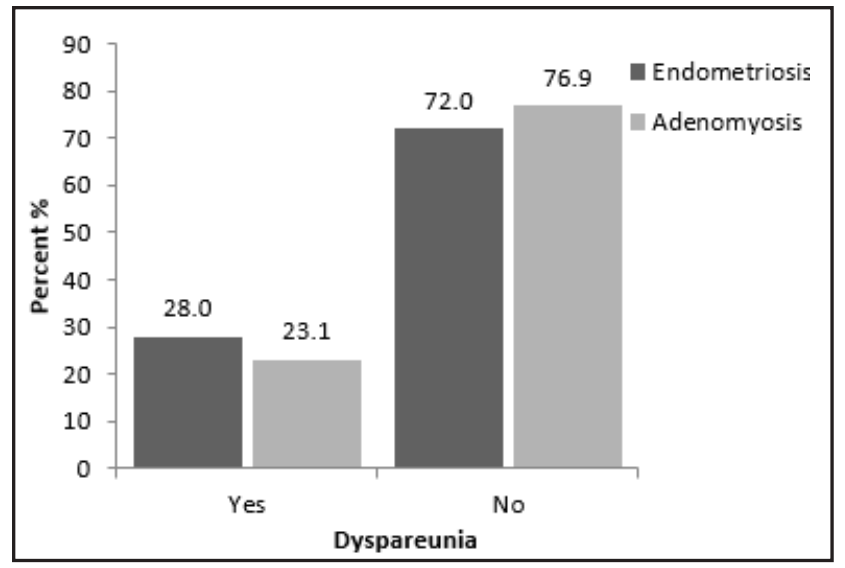

Fig. 8. Repartition (\%) of patients with dyspareunia and Ki67 positive in glandular cells in both groups.

There was no statistically significant difference according to the presence or the absence of dyspareunia in group 1 in patients with $\mathrm{KI} 67$ in glandular cells positive or negative ( $p=0.011>0.05)$. The same non-significant statistical difference was recorded in group 2 ( $p=0.346$ $>0.05$ ).

Biomarker Ki67 for stromal cells was positive for 27 patients with dyspareunia and 27 patients without this symptom, in group 1 (fig. 9). It was negative for 2 patients with dyspareunia and 5 patients without the symptom, in the same group. IHC Ki for stromal cells was positive for 6 patients with dyspareunia and 32 patients without it, in group 2 - and it was negative only for one patient without dyspareunia.

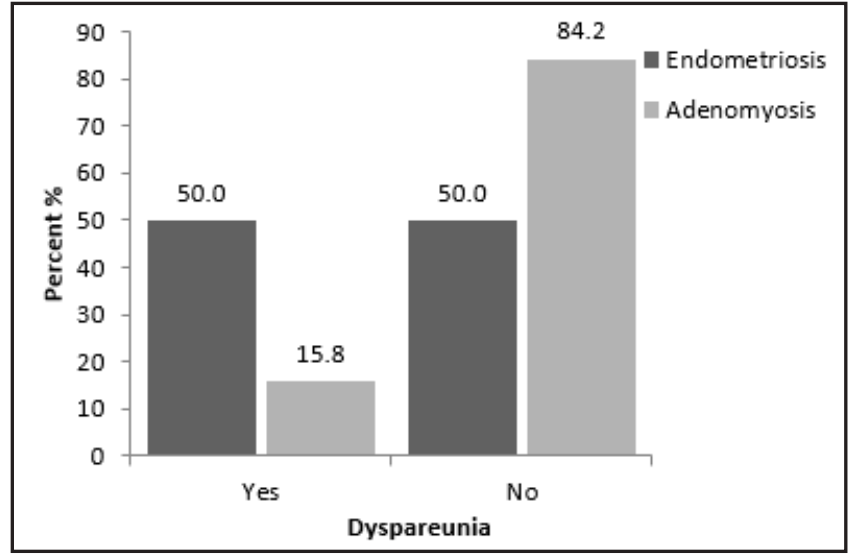

Fig. 9. Repartition (\%) of patients with dyspareunia and Ki67 positive in stromal cells in both groups

There was no statistically significant difference according to the presence or the absence of dyspareunia in group 1 in patients with $\mathrm{KI} 67$ in stromal cells positive or negative $(p=0.285>0.05)$. The same non-significant statistical difference was reported in group 2 ( $p=0.666>$ 0.05).

\section{Conclusions}

In our study, it seems that, in patients with endometriosis, chronic pelvic pain and dysmenorrhea are associated with the expression of IHC CD34. While pelvic pain seems to be associated with the expression of Ki67 in glandular cells, the absence of dysmenorrhea is related with the same IHC.

As CD34 is an angiogenesis marker and $\mathrm{Ki} 67$ is an aggressivity marker, pelvic pain could predict a more aggressive disease and with a higher spreading capacity in patients with endometriosis. In the same patients, and dysmenorrhea seems to be related with only with angiogenesis.

There was a tendency (although not statistically significant) for chronic pelvic pain and dysmenorrhea to be related to the presence of Ki67 in stromal cells, in endometriosis samples. The same, non-significant relation was observed between dyspareunia and CD34 and the absence of dyspareunia and Ki67 glandular. Equally, a nonsignificant correlation could be seen, in patients with adenomyosis, in-between the absence of pelvic pain, dysmenorrhea and dyspareunia and all three biomarkers.

Acknowledgments: This research was performed in the Center for Research and Development of the Morphological and Genetic Studies of Malignant Pathology from the Ovidius University of Constanta, POSCCE 2.2.1. Project ID: 1844, code SMIS: 48750, CEDMOG, contract 627/11.03.2014.

\section{References}

1.BROSENS, I., BENAGIANO, G. History of endometriosis. In: GIUDICE, L. C., EVERS J LH, HEALY DL. Endometriosis Science and Practice: Ed Blackwell Publishing Ltd, 2012; p 3-18. 
2.LEYENDECKER, G., WILDT, L. Uterine Peristalsis and the Development of Endometriosis and Adenomyosis. In: GIUDICE, L. C., EVERS J LH, HEALY DL. Endometriosis Science and Practice, Ed Blackwell Publishing Ltd, 2012, p 200-211.

3.RAPKIN, A.J ., NATHAN, L. Pelvic pain and dysmenorrhea. In: BEREK, J.S., NOVAK E., editors. Berek \& Novak's gynecology. 15th ed. Philadelphia (PA): Lippincott Williams \& Wilkins; 2012. pp. 470-504. 4. HEMMINGS, R., RIVARD, M., OLIVE, D.L., POLIQUIN-FLEURY, J., GAGNE, D., HUGO, P. Evaluation of risk factors associated with endometriosis. Fertil Steril. 2004:81:1513-1521.

5.TICA, V. La Fertilite. Contraception Fertilite Sexualite. 1996; 24(3):173. 6.PENCIU, R.C., IZVORANU, S., MOCANU, D., TICA, V. Pelvic Chronic Pain in Endometriosis Versus Adenomyosis. Proceedings of the 14th National Congress of Urogynecology and the National Conference of the Romanian Association for the Study of Pain, Ed. Bratila E; Cirstoiu M. Filodiritto Publisher, Bologna, Italy, 2017: 566-568.

7.PENCIU, R.C., IZVORANU, S., MOCANU, D., TICA, V. Correlation Between Dysmenorrhea and Endometriosis: Case Report. Proceedings of the 14th National Congress of Urogynecology and the National Conference of the Romanian Association for the Study of Pain, Ed. Bratila E; Cirstoiu M. Filodiritto Publisher, Bologna, Italy, 2017: 569570.

8.IZVORANU, S., PENCIU, R., MOCANU, I. D., TICA, V., et. al., Chronic Pelvic Pain of Gynecological Cause. Proceedings of the 14th National Congress of Urogynecology and the National Conference of the Romanian Association for the Study of Pain, Ed. Bratila E; Cirstoiu M. Filodiritto Publisher, Bologna, Italy, 2017: 463-465.

9.TICA, A.A., DUN E., TICA, V., COJOCARU, V., TICA, O.S., BERCEANU, $S$. The autonomic innervation of the uterus. A short review on pharmacological aspects. Gineco.ro 2011, 7(24):86-91.

10.TICA, V.I., TICA, A.A., CARLIG, V., BANICA, O.S. Magnesium ion inhibits spontaneous and induced contractions of the isolated uterine muscle. Gynecological Endocrinology. 2007;23(7):368-72.

11.TICA, V.I., COJ OCARU, V., TICA, O.S., BERCEANU, S., TICA, A.A. Cyclic-ADP-ribose/Ca 2+ system in uterine smooth muscle cells. Gineco.ro 2011, 7(26):193-194.

12.TICA, A.A., TICA, V.I., TICA, O., DUN, E., BERCEANU, S., TICA, I. Endothelin I activates the NAADP signaling complex on myometrial smooth muscle cell. (Endotelina I activeazã complexul NAADP. dependent în miometru.) Gineco.ro 2010, 6(22):254-255.

13.PENCIU, R.C., STERIU, L., IZVORANU, S., POSTOLACHE, I., TICA, A.A., MOCANU, D., TICA, O.S., SARBU, V., DEACU, M., BALTATESCU, G., TICA, I., PETCU, L., TICA, V.I., CD10, CD34 and Ki67 Immunohistochemical Markers Expression in Endometriosis and Adenomyosis. Rev. Chim. (Bucharest), 70, no. 4, 2019, p. 1323-1327. 14.STUART,L.N.CD34.PathologyOutlines.comw ebsite.http:// www.pathologyoutlines.com/topic/cdmarkerscd34.html.

15.COCU, M., THORNE, C., MATUSA, R., TICA, V., FLOREA, C., ASANDI, S., GIAQUINTO, C. Mother-to-child transmission of HIV infection in Romania: results from an education and prevention programme. AIDS Care. 2005;17(1):76.

16.TICA, V.I., MARES, P., GOUZES, C., BADEA, P., POPESCU, G., TICA, I. The variation of serum cortisol during ovarian stimulation for in vitro fertilization. Gynecological Endocrinology. 2008;24(1):12-17.
17.TICA, V., HEDON, B., EID, J ., AUDIBERT, F., BENOS, P., BOULOT, P., LAFFARGUE, F., VIALA, J.L. Determination of adverse reactions to the stimulation of ovulation in vitro fertilization. [Effets secondaires de la stimulation ovarienne dans le cadre de la fécondation in vitro.] Contraception Fertilité Sexualite. 1991; 19(7-8):580-582.

18.TICA, V.I, MARES, P., TEREN, O., TICA, I., TICA, A.A. Pre-emption dimensional study for obtaining statistically significant results for the variation of gGlutamyl-Ttransferase during ovarian stimulation. J Gastrointestin Liver Dis 2007;16(1):53-55.

19.TICA, I., TICA, O.S., NICOARA, A.D., TICA, V.I., TICA, A.A. Ovarian teratomas in a patient with Biedl Bardet syndrome, a rare association. Rom J Morphol Embryol 2016; 57(4):1403-1408.

20.PAREPA, I., MAZILU, L., SUCEVEANU, A., VOINEA, C., TICA, I. Hypocalcemic cardiomyopathy - a rare heart failure etiology in adult. Acta Endocrinologica (Buc), 2019;15(1):107-112.

21.TICA, V. Primary ovarian pregnancies. Gineco.ro 2011; 7(26):179180.

22.TICA, V. Laparoscopic ovarian drilling. Gineco.ro 2011; I7(25):119120.

23.TICA, V. Preeclampsia - an unsolved prophylaxis chapter. Gineco.ro 2012; 8(27):3-4.

24.TICA, V. A new method of anesthesia - Piritramide used intrathecally as a sole analgesic in surgery. Anesthesist 1988;3 7(10):116-116.

25.SUMATHI, V.P, MCCLUGGAGE, W.G. CD10 is useful in demonstrating endometrial stroma at ectopic sites and in confirming a diagnosis of endometriosis. J Clin Pathol. 2002 May; 55(5): 391-392.

26.KAHYAOGLU, I., KAHYAOGLU, S., MORALOGLU, O., ZERGEROGLU, S., SUT, N., BATIOGLU, S. Comparison of Ki-67 proliferative index between eutopic and ectopic endometrium: a case control study. Taiwan J Obstet Gynecol, 2012, 51(3):393-396.

27.BEGU, L., Statistica si software statistic, Ed. Clauet, Bucuresti, 1999

28.PETCU, L.C., Analiza statistica cu SPSS-Note de Curs, Ed. Ovidius University Press, Constanta, 2011, p.1-303

29.LUPU, G., PETCU, L.C., LUPU, E.C., Matematici aplicate $-i$ Biostatisticã, Ed. Virom, Constanta, 2006, p.221-293

30.POPA, M., Statistici multivariate - Aplicatii in psihologie, Ed.Polirom, Iasi 2010

31.WINGFIELD, M., MACPHERSON, A., HEALY, D.L., ROGERS, P.A. Cell proliferation is increased in the endometrium of women with endometriosis. Fertil Steril. 1995 Aug; 64(2):340-346.

32.MEENAKSHI, M., McCLUGGAGE, W.G. Vascular involvement in adenomyosis: report of a large series of a common phenomenon with observations on the pathogenesis of adenomyosis. Int J Gynecol Pathol. 2010 Mar; 29(2):117-121.

33.LI, S.F., NAKAYAMA, K., MASUZAWA, H., FUJ II, S. The number of proliferating cell nuclear antigen positive cells in endometriotic lesions differs from that in the endometrium. Analysis of PCNA positive cells during the menstrual cycle and in postmenopause. Virchows Arch A Pathol Anat Histopathol, 1993, 423(4):257-263.

34.YANG, J.H, WU, M.Y., CHEN, C.D., CHEN, M.J ., YANG, Y.S., HO, H.N. Altered apoptosis and proliferation in endometrial stromal cells of women with adenomyosis. Human Reproduction, Volume 22, Issue 4, 1 April 2007: 945-952.

$\overline{\text { Manuscript received: } 26.01 .2019}$ 